\title{
The Flipped Classroom: Motivating Student Nurses to Learn Independently
}

\author{
By Philip Davey*
}

\begin{abstract}
The flipped classroom has become an internationally recognised teaching strategy in higher education institutions including those which deliver nurse education and training. In 2014, the author "flipped" a first year module of the undergraduate nurse training programme at a University in the United Kingdom. Through the creation of on-line lectures and self-paced, independent e-learning activities students steered their own direction, pace and depth of learning. Class time was then dedicated to engaging students through discussions, debates and active learning exercises.

The aim of this research was to explore, using self-report questionnaires, the extent to which the flipped classroom stimulates student's motivation to engage with elearning activities. The research concluded that the flipped classroom delivery model motivates students to learn independently. The primary motivational stimuli included a heightened student enjoyment of e-learning that provided intrinsic motivation and peer group work as an extrinsic motivator.
\end{abstract}

Keywords: E-learning, Flipped classroom, Motivation, Nurse education, Nursing.

\section{Introduction}

The origins of the flipped classroom as a teaching strategy are unclear but is thought to have stemmed from the work of Eric Mazur in the 1980s around computer aided instruction and the lecturer acting as a coach (Hamdan et al. 2014). This teaching methodology has evolved over the last 30 years and in 2007 was formally recognised in the literature as the flipped classroom. Elearning is a considerable aspect of the flipped classroom, however little is known about the effect of this teaching strategy on student motivation to engage with the e-learning activities.

An initial literature search was conducted to explore the relationship between the e-learning component of the flipped classroom teaching approach and its effect on student motivation. The purpose of the literature review was to ascertain what studies have already been undertaken and what questions have already been answered in relation to student motivation to engage with on-line learning when they are presented through the flipped classroom. The initial search was performed through the Cumulative Index to Nursing and Allied Health Literature (CINHAL), Medline and Pubmed. Articles to be included, were limited to those published in the last 10 years. This rationale for this time period was to ensure all literature was contemporary and the full time span of the flipped classrooms existence would be covered. Articles were only included if they were available in English, although international citations were included as the flipped classroom has foundations in the United States of

\footnotetext{
${ }^{*}$ Senior Lecturer, University of West London, UK.
} 
America and has been adopted internationally in Higher Education Institutions (HEI's).

Six research papers were identified in the literature review and all papers described the flipped class-room within the context of a reversed teaching model where theoretical content is delivered through e-learning in advance of the interactive and applied face to face session with an academic. The literature demonstrated that the flipped classroom is an international pedagogical model with variations in how technology is used to engage learners. All authors described the fundamental use of students viewing online pre-recorded lectures, although there was variation on other e-learning strategies being included in the flipped classroom model. Variations included activities such as online discussion boards, video links, on-line reading and knowledge based self-assessments. The expectation in all cases was that following the e-learning activities, students would attend a face to face session prepared for collaborative learning through interactive activities and facilitated by an academic.

Butt (2014) and Findlay-Thomson and Mombourquette (2014) completed research studying the experience of students who have learnt through the flipped classroom teaching approach. The studies were completed using mixed methods approaches and participants were asked about their experiences of learning via the flipped classroom and how it impacted on their knowledge and assessment grades. Findings from the two studies were relatively consistent and participant opinion tended to be positive towards the use of the flipped classroom. The majority of participants agreed that they engaged effectively with the activities presented. A minority of students were opposed to learning in this way because they were not being taught directly by an academic and therefore had limited opportunity for asking questions. These studies concluded that mostly, students enjoy learning through the flipped classroom but these studies did not explore the participant's motivation to engage and complete the self guided learning activities.

Lin et al. (2014) explored student achievement in relation to e-learning through a quantitative research design which reviewed participant assessment results between two teaching strategies. Through comparison of a test and control group the researchers concluded that student achievement and assessment results showed no significant differences between the e-learning group and the traditional methods group. As a secondary element to the research, they explored student motivation to learn, comparing e-learning and traditional teaching strategies. Using a Learning Motivation Scale the research demonstrated that the student motivation prior to studying was equal for both groups but at the end of the module student motivation was $20 \%$ higher in the group who had learnt through e-learning. However, this study only explored the achievement and motivation in relation to e-learning not specifically in the context of the flipped classroom.

Al-Alwain (2013) identified there is an abundance of research regarding the implementation of e-learning in Higher Education Institutions (HEI's) and student satisfaction, but few were focused on student motivation in relation to 
e-learning. The researcher used a qualitative approach to explore intrinsic and extrinsic motivation factors in relation to e-learning. Through structured interviews, the researchers identified that when participants had access to the necessary resources, most participants engaged effectively with the learning activities. However, the participants did not feel they were learning to the same extent that they would have compared to traditional classroom methods. It was identified that this had a negative effect on their enthusiasm and motivation to engage. From the literature paper it was difficult to establish if this was due to student motivation or the quality of e-learning resources. If the researchers had evaluated the e-learning activities using the Attention, Relevance, Confidence, Satisfaction (ARCS) Model of Motivational Design. This instrument would have enabled the researchers to grade the quality of the resources and provide each activity with a motivational rating. A high motivational rating for the elearning resources could have provided additional confidence in the conclusions of the study.

To conclude the literature review, there appears to be a contradiction in the research findings with regard to student motivation and engagement with elearning activities. Lin et al. (2014) provided evidence that e-learning maintains student's achievement and boosts student motivation but the study was not specifically designed in the context of the flipped classroom. These findings are not supported by the work of Al-Alwain (2013), who identified that student motivation reduced when e-learning was used as a primary teaching method. He concluded that students valued the learning less than if they were being taught face to face by an academic. There is an evident lack of research with specific relevance to the flipped classroom and student motivation as most articles are in relation to e-learning and not specifically in the context of the flipped classroom. As the flipped classroom is not yet sufficiently established in the United Kingdom (UK), this literature review has been based on international research papers and there may be cultural considerations required when applying the literature to the experience of nursing students in the UK.

\section{Aims and Objectives}

The aim of this research was to evaluate whether being taught using the contextualized, e-learning activities of the flipped classroom, promoted high levels of student motivation to engage with these independent learning activities. The following research questions guide this study:

- Does learning through the flipped classroom stimulate high levels of motivation for student's nurses to engage with the prescribed e-learning activities?

- Does a students learning style impact on their motivation to engage with e-learning activities when presented through the flipped classroom? 
- Does an individual's engagement and enjoyment of e-learning activities motivate them to explore the learning topic in greater depth?

- Do individuals who have diagnosed, additional learning needs and therefore in receipt of learning support, engage with e-learning activities to the same level as those who do not receive learning support?

- Do students perceive that working in peer groups, as part of the flipped classroom, provides additional motivation to explore a topic in depth?

\section{Methodology}

This study adopted an original approach that aims to establish the motivation of students to engage with e-learning activities within the context of studying through the flipped classroom. The study involved surveying a cohort of students enrolled at a UK HEI in September 2014 to undertake an undergraduate programme of study in Nursing. One of the first year modules within the programme, Introduction to Professional Practice, had previously been redesigned applying the flipped classroom approach. The e-learning activities used in the Introduction to professional Practice module were independently evaluated by a group of students who did not form part of the participant group for this study. This group of students reviewed the resources and completed an evaluation questionnaire based on the ARCS Model of Motivational Design (Keller 1999). This model identifies a list of characteristics that a high quality e-learning resources should have. Students are then asked to score each characteristic using the Likert scale 0-5. If an elearning activity is scored highly it would be expected that students would have high levels of motivation to engage with it. As the quality of the e-learning resources could influence the research participant responses in the study, this objective assessment encourages confidence in the resources being used. The Introduction to Professional Practice module was delivered over seven separate weeks, timetabled periodically throughout the academic year. Students were asked to engage with e-learning activities at the beginning of each "Introduction to Practice" week. These e-learning activities included: video lecturers, reading materials and short answer question papers. The students would then meet in pre-arranged groups and complete short projects which aimed to further develop their theoretical knowledge of the topic. At the end of each Introduction to Practice week the students would attend a face to face session where the educationalist would contextualize the theory learnt and provide practical application through practical activities, student reports, problem based learning and critical reflection. 


\section{Data Collection}

Using a quantitative methodology, students were asked to complete a questionnaire at the end of the module. As the last session of this module required all students to be in the class room, face to face with an academic, convenience sampling was used to collect participant data. This involved sampling those students present using a questionnaire tool. This was issued in class for participants to complete and were then collected in before the participants left the session. This questionnaire was designed to measure student perceptions of their own motivation to engage, specifically with the elearning activities. The questionnaire had been designed using a five-point Likert scale from strongly agree to strongly disagree (Likert 1932). In order to answer the range of research questions, and to enable analysis of trends between student variables, the survey also included questions on demographics, learning style, time since last study and access to learning support due to specific learning needs.

\section{Data Analysis}

The data from this study was entered into a database and data analysis was conducted using IBM Statistical Package for the Social Science Version 20. This enabled a descriptive analysis of the statistics and a nominal measurement was used to classify the variables. The nominal scale forms the basis of Analysis of Variance (ANOVA) because there are consistent categories to compare. Demographic categories identified in the questionnaire were; gender, age, field of nursing, learning style and learning needs. Questions around engagement, enjoyment and interaction with peers offered a broader range of responses based on the 5 point Likert scale. A Chi Square analysis was used for categorical data with $\mathrm{p}$ level set at 0.05 .

\section{Ethical Considerations}

It is common practice in HEI's to obtain student feedback at the end of each module. Students were informed at the beginning of the module that the feedback received would be anonymous and with permission would be included in a research study for publication. Participants were issued with written and verbal information about the purpose of the study and the requirements on them as participants. Participants were informed that participation in the study was voluntary and that they could withdraw their participation from the study at any time without any fear of having an impact on their study or assessment outcomes. A section of the questionnaire asked the participants to sign that they consented to the information provided being used in the study. Ethical approval was sought from and approved by the Ethics Committee of the University of West London. 


\section{Results}

Out of 128 active students on the undergraduate BSc in Nursing programme of the September 2014 intake, 111 agreed to participate and all completed the questionnaire Of the active participants, the majority of participants were female $(91 \%)$ and a relatively small percentage were male (9\%). Although all participants were studying for the BSc in Nursing, there were three possible nursing pathways or fields of practice that they could follow. The largest proportion were following an adult nursing pathway (73\%) and smaller numbers were following a children's nursing pathway $(12 \%)$ or a mental health nursing pathway $(15 \%)$. Prior to commencing this module, students had undergone an assessment of their preferred learning style. This information was also noted on the questionnaire responses. Almost half of the respondents $(47 \%)$ stated they were visual learners, the remaining respondents stated they were either solitary learners (22\%) who preferred to read independently, kinesthetic learners $(21 \%)$ and the smallest proportion were auditory learners $(10 \%)$. Students who have an identified learning need are able to access learning support from a specialised team within the university. Thirty five percent of respondents stated that they received University learning support and therefore had a diagnosed learning need. The majority of students $(91 \%)$ had experience of formal education within 5 years of starting this course, with an additional $5 \%$ being in formal education with 10 years prior to the start of the course.

\section{Does a students learning style impact on their motivation to engage with e-learning activities when presented through the flipped classroom?}

The majority of students $(87.7 \%)$ were motivated to engage with the elearning activities and stated that they engaged to a high level. However, it was noticed that this was not consistent for all learning styles. Learning styles where engagement was at its highest were the auditory $(100 \%)$ and solitary (96\%) learners whilst to a lesser amount, kinesthetic (86\%) and visual (83\%) learners engaged. The data captured on learning style was correlated with the data on student's enjoyment of the e-learning activities. The results of this correlation were mirrored exactly the results for engagement demonstrating that there is correlation between student enjoyment of e-learning and their level of engagement. The results show that most students, from all learning styles, are motivated to engage with e-learning activities as part of the flipped classroom although some learning styles demonstrate a stronger preference.

\section{Does an individual's engagement with e-learning activities motivate them to explore the learning topic in greater depth?}

Overall, most students $(86 \%)$ stated that they had explored the topic in depth. However, of those students who also rated their engagement with the e- 
learning activities as being high, almost all (94\%) stated that they were motivated to explore the topics in great depth. Students would have based this on their previous experiences of e-learning and this statistic demonstrates that where motivation to learn through e-learning is high, the student motivation to explore and research the topic in greater depth is also high.

\section{Do the participants who have a diagnosed learning need and therefore in receipt of learning support engage with e-learning activities to the same level as those who do not receive learning support?}

For students who have diagnosed additional learning needs and in receipt of Additional Learning Support (ALS), the data suggests that students are highly motivated to engage with e-learning when it is presented as part of the flipped classroom. There is little difference between the results for those students who are in receipt of ALS and those who are not (ALS=81\% and no ALS $=85 \%, p=0.003$ ). This suggests that those students who have identified ALS needs are not disadvantaged by the e-learning aspects of the flipped classroom as results demonstrate that they engage well with e-learning. When considering the depth to which students explore the topic, the majority of students explore the topic in depth, those with additional learning support needs (81\%) and those who do not (85\%). This is an important finding as traditional teaching methods have well established limitations to engaging students with additional learning support needs, such as students with dyslexia.

\section{Do students perceive that working in peer groups, as part of the flipped classroom, motivate them to explore a topic in depth?}

Nearly all participants $(96 \%, \mathrm{p}=0.004)$ stated that completing the elearning activities in peer groups encouraged them to explore the topic in depth. This is a particularly interesting finding given that the activity briefs do not give any guidance on the topics to be explored or the depth to which the students explore those topics. The results suggest that students working in peer groups take responsibility for their own learning and learn a subject in depth in the absence of an academic. However, it is respected that, it is the application of student knowledge to nursing practice that makes the role of the academic in the flipped classroom a vital component.

\section{Discussion and Recommendations}

This study demonstrated that e-learning as part of the flipped classroom teaching method is very well received by students and is a suitable teaching method to accommodate all learning styles. Whilst it appears to lend itself more closely with the learning style of auditory learners, all students were able to engage and learn effectively. With reference to the reason student's felt motivated to engage, students stated that they enjoyed e-learning as part of the 
flipped classroom. As the flipped classroom offers vocationally relevant and practical e-learning activities, students identified high levels of enjoyment.

It has also been identified that e-learning as part of this teaching method does not disadvantage students who have additional learning needs. There were similar levels of motivation to engage with the e-learning between those students who have identified learning needs and those who do not. It could be argued that the flipped classroom offers a fairer opportunity to students with additional needs as the teaching resources are available in a variety of formats, they can be reviewed and re-reviewed by a student at their own pace. The demographic data of educational experience, gender, age and field of nursing also had no significant difference on a student's motivation to engage with elearning as part of the flipped classroom.

The study results also demonstrate that whilst enjoyment and motivation in the e-leaning activities resulted in the students exploring the e-topics in depth, this was not the only motivator of this. Working in peer groups was also a significant motivator for this. While e-learning requires the student to possess intrinsic motivation, which in the flipped classroom in encouraged through enjoyment and relevance, extrinsic motivation is provided through the peer learning elements of the e-learning activities. By having students working in pre-selected peer groups, students are able to have ownership of their educational direction of travel and have responsibility for their own leaning. Cordover and Lepper (1996) established that students who have responsibility for learning are and work in peer groups are most likely to search the topic in greater depth than if they work independently. By discussing the e-learning activities in groups and identifying topics and questions to answer, the students are not limited to the confides of a lecture theatre but are able to explore any avenue of the e-learning activity they wish and to any level of depth that they deem appropriate. One of the benefits of the flipped classroom is that the learning is not dictated by an academic, but facilitated so a student is enabled and motivated to develop a greater knowledge and understanding.

Whilst previous studies provided a conflicting view with regard to student engagement with e-learning, this study demonstrates that there are higher levels and more consistent engagement of students when the activities are; of a high standard, vocationally relevant, have a practical theme and are delivered as part of the flipped classroom. The flipped classroom is there as a tool to help support the teaching of pure knowledge, away from the pedagogy of lecturing to one of student self discover through the flipped classroom. However, the place of the academic is crucial in this education process as they are the people who not only prepare and support the e-learning activities, but also contextualize and develop the graduate skills of problem based learning, critical reflection and contextualized nursing practice through the face to face follow up session that follows the on-line learning. Flipping the classroom is a teaching strategy that requires careful planning and high standards of quality in order to be effective and meet the needs of the students. 


\section{Study Limitations}

This was a quantitative study of e-learning as part of the flipped classroom where one cohort of students was included and that makes this a relatively small study. There was a reliance on the students to self-report the data through the questionnaire and this may be subject to social response bias. It is recognized that all students are on the same study programme with similar educational backgrounds and whilst this makes them a homogenous group from an educational perspective the other demographic data collected demonstrated that they are significant differences across the study group. Whilst the majority of responses to the survey were female, this does reflect a typical pattern across educational nursing programmes and within the UK health care workforce.

\section{References}

Al-Alwani A (2013) Intrinsic and extrinsic motivators to e-learning. International Journal of Computer and Technology 12(6): 3131-3137.

Butt A (2014) Student views on the use of a flipped classroom approach. Business Education and Accreditation 6(1): 33-43.

Cordova D, Lepper M (1996) Intrinsic motivation and the process of learning. Journal of Educational Psychology 88(4): 715-730.

Findlay-Thomson S, Mombourquette P (2014) Evaluation of a flipped classroom in an undergraduate business course. Business Education and Accreditation 6(1): 6371.

Hamdan N, McKnight P, McKnight K, Arfstron KM (2014) A Review of Flipped Learning. Retrieved from http://goo.gl/w58G0q. [Accessed: 1 November 2014]

Keller J (1999) Using the ARCS motivational process in computer-based instruction and disctance education. New Directions for Teaching and Learning 78: 39-47.

Likert R (1932) A technique for the measurement of attitudes. Archives of Psychology 140: $1-55$.

Lin H, Chen W, Nien S (2014) The study of achievement and motivation by elearning. International Journal of Information and Education Technology 4(5): 421-425. 
